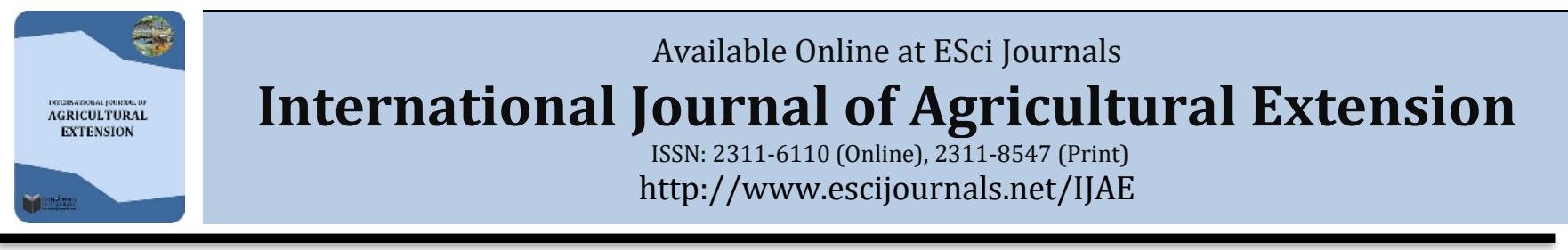

\title{
ACCESS AND USE OF VETERINARY SERVICES BY LIVESTOCK FARMERS IN WESTERN AGRICULTURAL ZONE OF NASARAWA STATE, NIGERIA
}

Emmanuel S. Salau

Department of Agricultural Economics \& Extension, Nasarawa State University Keffi, Nigeria.

\section{A B S T R A C T}

This study examined the access and use of veterinary services by small scale livestock farmers in the western agricultural zone of Nasarawa state. Two Local government areas (Karu and Keffi LGAs) were purposively selected from the zone for the study based on their popularity in small scale livestock production. Ten villages were randomly selected from each of the two selected LGAs to give a total of 20 villages. Six (6) livestock farmers were randomly selected from each of the 20 selected villages giving a total of 120 respondents. Data were collected through a structured interview schedule. Data were analyzed using both descriptive statistics and a multiple regression model using SPSS software. The results show that the majority (75.2\%) of the respondents were male. Their mean age was 35years which implies that the livestock farmers were mostly young people. Their average year of farming experience was 10 years. Half (50\%) of them had tertiary education, indicating the enhanced capacity to access and use veterinary services. The major veterinary services adopted by the respondents were treatment of sick animals (93.3\%), vaccination (87.2\%), castration (65.0\%) and Sanitary/Fumigation practices (41\%) among others. The regression analysis showed that four variables had a significant effect (1\%) on the level of use of veterinary services by the respondents. These were gender ( $p \leq 0.417)$, level of education ( $p \leq 0.603)$, number of extension visits ( $p \leq 0.607)$ and membership of social organisations ( $\mathrm{p} \leq 0.670)$. Lack of money to acquire vaccines and drugs $(X=2.3)$, high cost of veterinary services (X $=2.3)$ and far distance to veterinary centres $(X=2.0)$ were the major constraints to use of veterinary services. It was recommended that extension agents should encourage the farmers to join cooperative groups to enhance easy access to credit to procure veterinary inputs.

Keywords: Access, Use, Veterinary Services, Livestock Farmers new technology, adoption, Farmers Research Group.

\section{INTRODUCTION}

Livestock production is a source of employment and livelihood to many people in Nasarawa state and Nigeria as a whole. A large percentage of the people especially in the rural areas, satisfy their subsistence needs through livestock production which involves the rearing and marketing of livestock such as cattle, sheep, goats, pigs, and poultry. However, livestock diseases remain a veritable threat to the animal production industry in Nigeria. According to Olugasa et al. (2013), the poultry industry is even more devastated by viral infections such as Newcastle disease and Infectious bursal disease (Gumboru) in spite of several attempts at vaccinations.

* Corresponding Author:

Email: emmasalau@yahoo.com

(C) 2019 ESci Journals Publishing. All rights reserved.
Some of the reasons for these may be vaccine failure and the involvement of quacks in fighting these endemic animal diseases in the country. According to de Haan \& Umali (1992), the provision of veterinary services is a key component to the success of livestock production. Veterinary services are also considered as a vehicle for reducing poverty among the small scale rural livestock farmers. Inputs such as feed, water, proper housing, good management practices and record keeping are essential for profitable livestock production but without proper animal health practices there will be reduced efficiency and optimal profits. The role of the Veterinarian is to advise the livestock farmer on proper herd health management practices such as proper de-worming, vaccination, nutrition, environmental sanitation, disease prevention and control and treatment of animal illnesses. 
Bamaiyi (2013) observed that most animal production activities in Nigeria are located in rural and remote areas which are inaccessible to proper veterinary services and many that are accessible find the high cost of veterinary services prohibitive. Hence the farmers resort to the easily available quacks that wreak havoc on the animal industry by using expired vaccines, fake drugs and wrong prescriptions for treating diseases. Also, Olugasa et al. (2013) reported the prevalence of sub-standard and all manner of low-quality drugs and vaccines in the Nigerian market which are ignorantly purchased and used by livestock farmers.

Despite the growing importance of veterinary extension service as a tool for sustainable livestock production for family and national food security, many rural farmers seem to have poor access to available services. In the case of Nasarawa state and the western agricultural zone in particular, despite the proliferation of veterinary stores in the township and local markets, it is not certain whether the small scale livestock farmers have actually adopted such services.

Objectives of the Study: The main objective of the study is to assess the level of access and use of veterinary services by livestock farmers in the Western Agricultural zone of Nasarawa State. The specific objectives are to:

- describe the socio-economic characteristics of small scale livestock farmers in the study area;

- identify the types of livestock produced by the respondents;

- determine the types of veterinary services mostly used by the respondents;

- assess the effect of respondents' socio-economic characteristics on their level of adoption of veterinary services;

- identify the factors militating against the adoption of improved veterinary services by the respondents.

\section{METHODOLOGY}

This study was carried out in the western agricultural zone of Nasarawa state, Nigeria which covers four Local Government Areas (LGAs) of Karu, Keffi, Nasarawa and Toto. Western Agricultural zone is one of the three agricultural zones in the state. The agricultural zone is sub-divided into smaller administrative units such as Extension Areas, Extension Blocks and Extension Cells for ease of extension service delivery.
A multi-stage sampling technique was used for the study. First, two extension blocks were randomly selected from each of the two Extension Areas in the zone to give a total of four extension blocks selected. Secondly, two livestock producing communities were randomly selected from each of the four selected blocks to give eight (8) communities. Stage three was the selection of 15 livestock farmers using simple random sampling technique from each of the eight (8) communities giving a total of 120 respondents for the survey. However, only 117 completed questionnaires were valid and used for analysis and results presentation.

Primary data were collected using a structured interview schedule which was administered to the respondents with the help the Extension agents in the area. The interview schedule was framed in such a way that it covered all the objectives of the study. Data were analyzed using both descriptive and inferential statistics. The descriptive statistics (percentage and mean scores) were used to achieve objectives 1, 2, 3 and 5 while a multiple regression model was used to achieve objective 4 .

\section{Model Specification}

$Y=a+b 1 \times 1+b 2 \times 2+b 3 \times 3+b 4 \times 4+b 5 \times 5+b 6 \times 6+----\mu$.

Where:

$Y=$ Level of Use of veterinary services (Percentage)

$\mathrm{X} 1$ = Age of farmers (years)

$\mathrm{X} 2$ = Sex of the respondent (male=1. Female=2)

$\mathrm{X} 3$ = Educational level (No of years spent in school)

$\mathrm{X} 4=$ Number of veterinary extension contacts per year

$\mathrm{X} 5$ = Years of livestock farming experience

$\mathrm{X} 6=$ Membership of social organization (Yes =1, No = 0)

$\mathrm{X} 7=$ Access to Credit (Amount of loan obtained in naira)

$\mathrm{X} 8=$ Annual income $(\mathrm{N})$

b1-b8 = Regression coefficients

$\mathrm{a}=$ Constant term

$\mu=$ Error term

\section{RESULTS AND DISCUSSIONS}

Socio-Economic Characteristics of Respondents: Table 1 shows that the majority (65.8\%) of the respondents were between the age of 21-40 years with the mean age of 35 years. This shows that the livestock farmers in the study area were mostly young people. Younger farmers are expected to be more innovative than the older ones hence their ability to adopt innovations 
more readily. The table further shows that majority (78.8\%) of the respondents were males while $21.2 \%$ were females, implying that men were more actively engaged in livestock production than the women in the area. The majority (59.8\%) of the respondents were single. This further confirms that most of them were young people who are usually venturous. A greater proportion $(41.9 \%)$ of the respondents had tertiary education, $39.3 \%$ had secondary education and $13.7 \%$ had no formal education while $5.1 \%$ of the respondents had primary education. This implies that most of the respondents had various levels of formal education. Education plays a vital role in the adoption of veterinary services. Adebayo \& Adeola (2005) reported that education level has a significant and positive relationship with an average production of poultry. This means the higher the educational level of farmers the higher the productivity of their farms. Therefore, farms managed by educated entrepreneurs are likely to perform better than those managed by illiterate farmers. The majority (64.1\%) of the respondents obtained their information on veterinary services from mass media and $34.2 \%$ obtained theirs from extension agents. Mass media such as radio, television and print media are usually adjudged as the most effective channels of communication because of their ability to reach a large number of audience at the same time within a short time. However, in his study of Livestock farmers' awareness, access and benefits of Veterinary Extension Services in Southwestern Nigeria, Oladele (2004) found out that Office call was the most utilised (71.2\%) extension method by the respondents.
Table 1 also shows that the mean annual income of respondents was N104, 948. Income level usually shows a significant positive relationship to technology adoption by respondents. It is expected that the more money that is available to the respondents, the more they should be able to access veterinary services. Table 1 also shows that the majority (59.9\%) of the respondents had no access to credit while $40.2 \%$ had access to credit. This might be because many of the farmers do not belong to any cooperative group. The table also shows that majority (53.0\%) had no access to extension visits, $20.5 \%$ of the respondents had access to extension agents at least twice a month, while $4.3 \%$ had access to extension services only once a month. Lack of extension contacts is responsible for the wrong application of veterinary drugs among livestock farmers in most cases. It was also revealed that the majority (51.3\%) did not belong to any cooperative organization. This implies that most of the respondents might find it difficult to access loan to boost their livestock production.

Table 1 also shows that a larger proportion of the respondents (37.6\%) had 1-5 years of experience in livestock farming experience with the mean years of farming experience as 9 years. This implies that most of the respondents were new entrants in the livestock farming business and thus may lack some vital technical skills in the use of veterinary services. Ayinde et al. (2010) found that education level of farmers; farming experience; farm size; access to extension agents and access to credit have a significant and positive influence on adoption.

Table 1. Socioeconomics Characteristics of Respondents ( $N=117)$.

\begin{tabular}{|c|c|c|c|}
\hline Characteristics & Frequency & Percentage & Mean (X) \\
\hline \multicolumn{4}{|c|}{ Age (Years) } \\
\hline $1-20$ & 9 & 7.7 & \\
\hline $21-40$ & 77 & 65.8 & 35.37 \\
\hline $41-60$ & 28 & 23.9 & \\
\hline Above 60 & 3 & 2.6 & \\
\hline \multicolumn{4}{|c|}{ Sex } \\
\hline Male & 88 & 75.2 & \\
\hline Female & 29 & 24.8 & \\
\hline \multicolumn{4}{|l|}{ Marital status } \\
\hline Married & 44 & 37.6 & \\
\hline Single & 70 & 59.8 & \\
\hline Divorced & 3 & 2.6 & \\
\hline
\end{tabular}




\begin{tabular}{|c|c|c|c|}
\hline \multicolumn{4}{|c|}{ Educational status } \\
\hline Non formal education & 16 & 13.7 & \\
\hline Primary & 6 & 5.1 & \\
\hline Secondary & 46 & 39.3 & \\
\hline Tertiary & 49 & 41.9 & \\
\hline \multicolumn{4}{|c|}{ Annual income in naira $(\mathrm{N})$} \\
\hline $1,000-50,000$ & 36 & 30.8 & \\
\hline $51,000-100,000$ & 40 & 34.2 & \\
\hline $101,000-150,000$ & 20 & 17.1 & \\
\hline $151,000-200,000$ & 8 & 6.8 & N104, 948.71 \\
\hline Above 200,000 & 13 & 11.11 & \\
\hline \multicolumn{4}{|c|}{ Access to credit } \\
\hline Yes & 47 & 40.2 & \\
\hline No & 70 & 59.8 & \\
\hline \multicolumn{4}{|c|}{ Source of information on Vet services } \\
\hline Neighbours/Fellow farmers & 2 & 1.7 & \\
\hline Extension agents & 40 & 34.2 & \\
\hline Mass media & 75 & 64.1 & \\
\hline \multicolumn{4}{|c|}{ No. of extension visit per month } \\
\hline No visit at all & 62 & 53.0 & \\
\hline Once & 9 & 7.7 & \\
\hline Twice & 24 & 20.5 & \\
\hline More than twice per month & 22 & 18.8 & \\
\hline \multicolumn{4}{|c|}{ Membership of social organization } \\
\hline Yes & 57 & 48.7 & \\
\hline No & 60 & 51.3 & \\
\hline \multicolumn{4}{|c|}{ Years of experience in Livestock farming } \\
\hline $1-5$ & 44 & 37.6 & \\
\hline $6-10$ & 46 & 39.3 & 10.37years \\
\hline $11-15$ & 21 & 17.9 & \\
\hline Above 15 & 6 & 5.1 & \\
\hline
\end{tabular}

Source: field survey, 2016.

Table 2. Types of livestock kept by the respondents.

\begin{tabular}{lcc}
\hline Livestock type & Frequency & Percentage \\
\hline Poultry & 59 & 50.4 \\
Sheep and goat & 90 & 76.9 \\
Cattle & 45 & 38.5
\end{tabular}

*Multiple responses were allowed

Table 3. Types of veterinary services mostly used by the respondents.

\begin{tabular}{lcc}
\hline Services & Frequency & Percentage \\
\hline Treatment of sick animals & 108 & 92.3 \\
Vaccination & 102 & 87.2 \\
De-beaking & 31 & 26.5 \\
Sanitary/Fumigation practices & 48 & 41.0 \\
Castration & 76 & 65.0 \\
Routine de-worming of animals & 37 & 31.6 \\
\hline
\end{tabular}


Types of Livestock Produced by the Respondents: On the types of livestock kept by the respondents in the study area, the majority (76.9\%) of the respondents were into sheep and goat production, poultry accounted for $50.4 \%$ while cattle production accounted for only 39.5\% respondents. This implies that the respondents were mostly involved into small ruminants and poultry production. Pig production was not popular in area due to the religious and cultural norms prevalent in the area.

Types of Veterinary Services Used by the Respondents: Veterinary services that were mostly used by the respondents include treatment of sick animals (92.3\%); routine vaccination (87.2\%); castration (65.0\%) and sanitary/fumigation practices $(41.0 \%)$. The results show a high level of patronage of most of the veterinary services by the respondents.

Constraints faced by the Respondents: Table 4 shows the constraints to the effective adoption of veterinary services by the respondents. The major constraints expressed by the respondents were the high cost of veterinary services $(X=2.3)$; lack of/inadequate funds to acquire vaccines or drugs $(X=2.3)$ and distance to veterinary clinic/shops $(X=2.0)$. This implies that lowincome status of the respondents and the location of veterinary stores and veterinarians mostly in the township were responsible for the poor access to these vital services by rural farmers.

This finding agrees with that of Olugasa et al. (2013) who reported that most animal production activities are located in rural areas or remote areas inaccessible to proper veterinary services and many that are accessible find the high cost of veterinary services prohibitive. Hence, they resort to the easily available quacks that wreak havoc on the animal industry by using expired vaccines, fake drugs and wrong prescriptions for treating diseases.

Table 4. Constraints to the adoption of veterinary services.

\begin{tabular}{lcc}
\hline Constraints & Mean score & Decision \\
\hline The high cost of veterinary services & 2.3 & Serious \\
Inadequate funds to acquire vaccines or drugs & 2.3 & Serious \\
Distance to veterinary clinic/shops & 2.0 & Serious \\
Low educational level & 1.8 & Not Serious \\
Scarcity of adequate drugs and vaccines & 1.7 & Not Serious \\
Lack of adequate awareness of veterinary services & 1.5 & Not Serious
\end{tabular}

Decision rule: Any factor with a mean of 2 and above = Serious constraint while less than 2 is not a serious constraint as perceived by the respondents.

\section{Effects of Respondents' Socio-economic} Characteristics on their level of Use of Veterinary Services: Table 5 shows the results of regression analysis of the effect of respondents' socioeconomic characteristics on their level of use of veterinary services. Among the socio-economic characteristics analysed, the education level of the respondents, marital status, household size, and income were all positively related to the respondents' access to veterinary services. On the other hand, the age, membership of social organization and years of experience were negatively related to the respondents' access to veterinary services. This implies that older farmers were unlikely to adopt veterinary services compared to the younger ones. The results also show that as income increases adoption level increases because livestock farmers can afford to pay for veterinary services. Income of the respondents was significant at $5 \%$, membership of social organization was significant at $10 \%$, while marital status and years of experience were both significant at $1 \%$. The R-square value is $0.941 \%$, indicating that $94 \%$ of the variation in the dependent variable was explained by the independent variables.

In a related study, Salau et al. (2014) found that age of the respondents, educational level, formal training in fisheries, years of farming experience, income level and membership of social organizations all showed positive relationship with rate of adoption of improved fisheries technologies in the southern agricultural zone of Nasarawa state Nigeria. 
Table 5. Regression analysis of the effect of socio-economic characteristics on the level of adoption of veterinary services

\begin{tabular}{lccc}
\hline Variables & Coefficients & Standard error & t-value \\
\hline Constant & -1.180 & 3.519 & -0.335 \\
Sex & 0.261 & 0.628 & $0.417^{*}$ \\
Age & -0.704 & 0.606 & -1.162 \\
Education level & 0.263 & 0.437 & $0.603^{*}$ \\
Marital status & 2.129 & 0.844 & 2.522 \\
Household size & 0.934 & 0.042 & 22.345 \\
Farming experience & -1.088 & 0.283 & -3.847 \\
Extension visit & 0.021 & 0.035 & $0.607^{*}$ \\
Membership of social organization & -0.027 & 0.040 & $-0.670^{*}$ \\
Income level & 0.572 & 0.237 & 2.413 \\
\hline
\end{tabular}

$\mathrm{R}^{2}=0.941,{ }^{*}$ significant at $10 \%$.

\section{CONCLUSION AND RECOMMENDATIONS}

Based on the results of the study, it was concluded that livestock farmers in the study area had a high level of access to veterinary services. However, the effective utilisation of such veterinary services was hampered by certain constraints such as high cost of veterinary services, lack of/inadequate funds to acquire vaccines or drugs and distance to veterinary clinic/shops. Based on these findings the study recommended that the government should subsidize the cost of veterinary drugs to make them more affordable by resource-poor farmers. Extension agents should encourage and mobilize livestock farmers to form cooperative organizations because this could help them get a loan to acquire veterinary services with ease. The state ADP in conjunction with the Local Government Council should set up veterinary clinics/drug centres in livestock producing areas to enhance easy access by the farmers.

\section{REFERENCES}

Adebayo, 0.0. \& Adeola, R.G. (2005). Socio-economic factors affecting poultry farmers in Ejigbo Local Government Area of Osun State. Journal of Human Ecology, 18(1), 39-41.

Ayinde, 0. E, Adewumi M. O, Olatunji GB, \& Babalola 0 A. (2010). Determinants of Adoption of Downy Mildew Resistant Maize by Small-Scale Farmers in Kwara State, Nigeria. Global Journal of Science Frontier Research, 10.

Bamaiyi, P.H. (2013). Factors Militating Against Animal
Production in Nigeria. International Journal of Livestock, 3(2).

Doss, C.R. (2003). Understanding Farm-level Technology Adoption: Lessons Learned from CIMMYT's Micro Surveys in Eastern Africa. CIMMYT. Hammond, J.A.D., Fielding and S.C Bishop (1997). "Prospect for plant Anthelmintics in Tropical veterinary medicine: Veterinary Research Communication, 21, 213-226.

De Haan C. \& Umali D.L. (1992). Public and Private Sector Roles in the Supply of Veterinary Services. In: Faramade, I.A. et.al. (2016). Factors Limiting Effective Veterinary Practice in Oyo State, Nigeria. Vom Journal of Veterinary Science, 11, 126-134.

Oladele, O.I. (2004). Livestock farmers' awareness, access and benefits of veterinary extension services in south western, Nigeria. Livestock Research for Rural Development, 16(6).

Olugasa, B.0; Emikpe, B.0; Oluwayelu, D.0; Cadmus, S.I.B; Ayinmode; A.B \& Oluwole, O.E. (2013). Field evaluation of immunogenicity of five commercial vaccines against Newcastle disease in poultry farms in Ibadan, Nigeria. Nigerian Veterinary Journal, 33(2), 475-482.

Salau, E. S., Lawee, A. Y., Luka, E. G. \& Bello, D. (2014). Adoption of Improved Fisheries Technologies by Fish Farmers in Southern Agricultural Zone of Nasarawa State, Nigeria. Journal of Agricultural Extension and Rural Development, 6(11), 339-346. 